\title{
CONFLICT REDUCTION IN CROSS-FUNCTIONAL PROJECTS IN SOUTH AFRICAN AUTOMOTIVE FIRMS
}

\author{
T Mueller \& H Parker, University of Cape Town; A Ross, Michigan State University
}

\begin{abstract}
Purpose: The purpose of this article is to explore whether certain organisational control mechanisms can reduce conflict associated with cross-functional projects.

Methodology: This is an exploratory study and individuals who had recently engaged in a cross-functional process improvement or change implementation project at automotives firm in South Africa were surveyed. The information collected from the survey was analysed using exploratory factor analysis and correlation analysis.

Findings: The results of this study indicate that of the three control mechanisms examined, formalisation in project structure had the strongest association with a reduction in conflict. Reward systems that reward both the team as well as the individual were also found to have a significant association with a reduction in conflict. Use of performance measurement systems aimed at achieving strategic alignment did not have an association with conflict reduction in the organisation.
\end{abstract}

Implications: These findings yield the following implications for management practice. Firstly managers need to be conscious that initiatives such as process improvement projects that require individuals from different functions to work together can often result in conflict. Secondly, this conflict can be reduced by formalizing roles and responsibilities and decreasing ambiguity in the project. Thirdly, design of reward systems that incentivise both the cross-functional team as well as the individual can also help to reduce conflict.

Contribution and value: This study has shed light on the role of certain organisational control mechanisms on reducing conflict associated with cross-functional projects. It has also contributed to our understanding of how formalisation in project structure influences conflict in comparison to how performance measurement and reward systems influence conflict.

Key words and phrases: Conflict, Cross-functional Projects, Teamwork, Formalisation, Performance Measurement, Reward Systems, Automotive, Manufacturing.

\section{INTRODUCTION}

A difference in perspectives between individuals from different groups often results in conflict when these different groups are mandated to work together (Gerwin, 2004). Conflict among project team members who are engaged in process improvement or change implementation projects can have a negative influence on project outcomes (Dawes \& Massey, 2005), delay the speed of launching new products or services, decrease final quality, or increase costs to the point of corporate failure.

"When the project is complex, involving input and work from several departments or groups and possibly other contributions from several outside contractors, the intricate process of coordinating the work and timing of these inputs is difficult. When the groups are in conflict, the process is almost impossible." (Mantel, Meredith, Shafer \& Sutton, 2005:62)

Reducing conflict has the potential to have several positive effects on project success. The most widely reported benefit of reducing conflict amongst different groups in projects is the reduction of time losses incurred by individuals involved in the project (Phillips, 2008).

This paper starts with discussing the purpose of this study. Relevant literature is then discussed and hypotheses are developed. The methodology employed in this study is described and findings discussed. Finally conclusions are drawn and areas for future research and the implications of this research for management practice are noted. 


\section{PURPOSE}

Numerous researchers have highlighted the benefits of involving individuals from multiple functions in projects (Gerwin, 2004). While these benefits are recognized, it is also acknowledged that crossfunctional projects are associated with certain challenges, such as difficulties in co-coordinating individuals from different functions, and managing conflict that arises in trying to align diverse goals (Mantel, Meredith, Shafer \& Sutton, 2005). This paper aims to contribute to our understanding of how conflict associated with cross-functional projects can be reduced. In particular this investigation explores how specific organizational control mechanisms can be employed to reduce conflict during cross-functional projects; thereby facilitating much needed integration between different functional groups.

The objectives of this study are to contribute to the understanding of which organisational control mechanisms have a significant effect on the level of conflict perceived by individuals in crossfunctional projects. Three organizational control factors were selected for in-depth investigation based on a review of the literature related to cross-functional conflict, and based on factors highlighted by managers who have experience working in cross-functional projects. These managers were interviewed by the researchers. The organisational control factors highlighted by the managers interviewed included performance measurement systems, reward systems and the degree of formalization within the project. Guided, in part, by managers' perceptions, these factors were selected for further investigation.

The research question that this study sought to address is: Can certain organisational control mechanisms be used to reduce conflict amongst individuals from different functional groups who need to work together to achieve a specific change or process improvement on behalf of their organization?

In particular this study sought to understand to what extent performance measurement systems, reward systems and the degree of formalization within the project structure were associated with lower levels of conflict during cross-functional projects. How performance measurement and reward systems influence conflict compared to project structure has not been explicitly examined. Therefore this study aims to shed light on whether formalization in project structure has a stronger influence on conflict between functions than performance and reward systems. This study also aimed to ascertain whether associations between formalization in project structure, performance measurement and reward systems indicate that they worked in a complementary way or whether they worked in a competing way.

\section{BACKGROUND AND HYPOTHESES DEVELOPMENT}

This section provides an overview of the South African automotive industry, the need for crossfunctional work and how cross-functional work can cause conflict to arise. The second part of this section develops the hypotheses that are tested in this study.

In South Africa the automotive industry is an important contributor to the economy. The automotive industry contributes approximately $7.5 \%$ to South Africa's Gross Domestic Product (GDP). It also provides employment for more than 36000 people (National association of automobile manufacturers of South Africa, 2008). The South African government has identified the automotive industry as a key growth sector and has been a strong driver of programmes such as the motor industry development programme (MIDP). This programme was initiated in 1995 to assist automotive manufacturers and component manufacturers through the reduction of tariffs, the introduction of duty-free imports of components, duty rebate credits on exports and the lifting of local content policies (Kaplan, 2004). While support from programmes such as the MIDP programme is acknowledged, researchers such as Barnes, Kaplinsky and Morris (2003) argue that the South African Automotive industry's success in exporting has been more as a result of the industry's efforts at improving its efficiency rather than as a result of the MIDP support programme (Kaplan, 2004).

The South African automotive industry currently faces pressures which are similar to those pressures being experienced by automotive industries globally. These pressures include an increasing pace of change and innovation. The automotive industry in particular has gone through a difficult phase in 
recent years. Increasing product variety and cost pressure have required higher levels of operational efficiency, which has resulted in more projects focused on process re-engineering and process improvement. The implementation of a change such as process re-engineering often necessitates the involvement of persons across multiple different functions, and has the potential to cause conflict amongst them. Conflict in turn creates frictional losses that inhibit progress and thus directly affects the bottom line, as time and capital are wasted through trying to resolve conflict.

Research on cross-functional conflict has been done primarily in the context of new product development (Jassawalla \& Sashittal, 2000). However, considerably less is understood about the occurrence of cross-functional conflict in projects focused on implementing a change or in the context of process improvement.

Cross-functional projects are burdensome in that they create additional tasks for those involved. The projects are furthermore characterized by great ambiguity about everyone's role, and the interaction process. Gerwin (2004) notes that tasks involving different groups, that are complex, interdependent and unclear have a strong tendency for disharmony. It has been suggested that if the causes of conflict within an organisation can be better understood and managed constructively, conflict can lead to more innovation and creativity (OPP Report, 2008).

Dawes and Massey (2005) found that cross-functional conflict is often unhealthy and is associated with dysfunctional behaviours. It is thus critical that conflict be managed as effectively as possible, as reducing the level of cross-functional conflict holds potential benefit for any organisation. A recent study done in the UK showed that on average employees within firms spend two hours per week trying to resolve conflict. For the UK, this adds up to 370 million working days lost per year due to conflict (OPP Report, 2008). This study also found that conflict results in losses that are less tangible but of equal concern. These include a reduction in an employee's motivation and an increase in his or her anger and frustration.

In examining the organisational factors that may reduce conflict; this study focuses on the role of performance measurement systems, reward structure and formalisation of roles and responsibilities.

\section{Performance Measurement Systems}

Strategic alignment between different groups can be achieved by means of performance measurement systems; however when performance measurement systems do not create alignment between groups, significant problems in coordinating tasks will arise (Gerwin, 2004).

Perks and Riihela (2004) stress the importance of a shared understanding of goals in cross-functional projects. Griffin, Neal and Parker (2007) draw attention to how important performance measurement systems are in inducing team orientated behaviour by individuals. When performance measures do not align the interests of diverse groups, Cadsby, Song and Tapon (2008) observe that a loss in productivity will arise due to conflicting interests. It is thus suggested that:

Hypothesis 1: The use of performance measurement systems aimed at strategic alignment is negatively associated with conflict in cross-functional projects.

\section{Reward Structure}

The use of rewards to incentivise employees to increase their productivity has been well documented (Cadsby et al., 2008). Cadsby et al. (2008) have found that reward structure had a significant effect on how employees were motivated. They also warn that excessive focus on individual "pay-forperformance" may result in unintended negative consequences for the firm as a whole.

In order to obtain the best performance from people, Chenhall (2005) stresses the need to balance individual recognition with recognition for the team. Reward systems, however, often evaluate people on functionally-based performance dimensions without considering the company's overall goals or the objectives of other departments (Griffin et al., 2007). Many researchers have outlined the importance 
of team recognition and rewards for cross-functional integration, Griffin et al (2007:343) support this and their findings show that "team-orientated behaviours are distinct from individual task performance". In addition to this, they also acknowledge that the design of performance measurement and reward systems to promote team-orientated behaviour is very difficult

Most organizational reward systems either lack achievement-based recognitions or, if available, are focused only on the individual. In order to rectify this problem organizations can either incorporate team recognition into their existing reward systems or develop alternative systems for rewarding team performance in parallel to individuals' functional performance expectations (Griffin et al., 2007). Cadsby at al. (2008) have found that the climate created by a reward system will strongly influence an employee's behaviour towards a team project. It is thus argued that:

Hypothesis 2: A Reward System that recognizes individual as well as team achievements is negatively associated with conflict in cross-functional projects.

\section{Formalization}

In this study formalization is defined as the degree to which roles and processes are explicit rather than implicit (Fishman, 2000) There is divergence in the literature regarding the effect of formalization on organizational performance (Bodewes, 2002). Gerwin (2004) for example, argues that setting too specific a structure for complicated, uncertain, and hard tasks is counterproductive and that organic structures or loosely coupled networks of workers are better adapted to dynamic environments. Other studies have shown that effective cross-functional interfacing and integration requires a certain degree of formalization (Fishman, 2000). Griffin et al. (2007) show how role clarity has a positive influence on performance both on an individual level as well as on a team level.

Formalisation has been found to facilitate coordination between corporate functions within the firm as well as beyond the firm that is between the firm, its customers and its suppliers (Parker, 2007). Conflict is often caused by problems coordinating different people or groups working on a project, Gerwin (2004) notes that the use of formal rules may in certain contexts facilitate coordination and reduce conflict. Based on these observations the following hypothesis is suggested:

Hypothesis 3: Formalization decreases ambiguity and is therefore negatively associated with conflict in cross-functional projects.

These hypothesized relationships are summarized in Figure 1.

Figure 1: Organisational control mechanisms and conflict

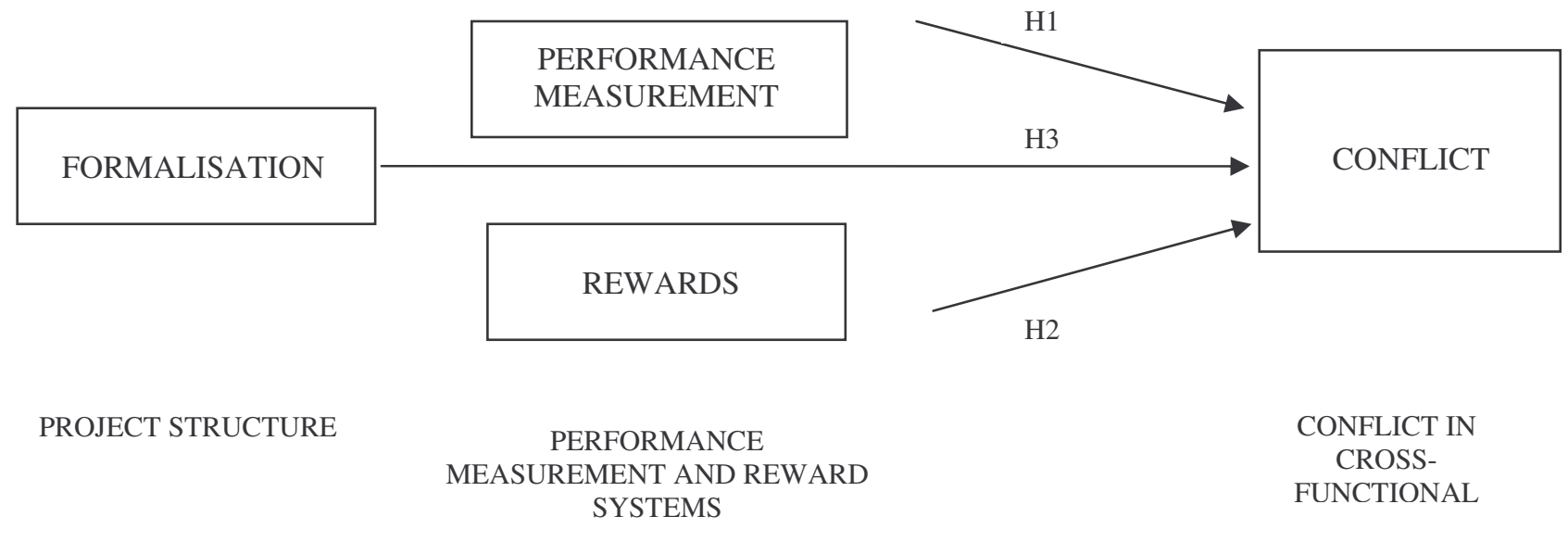




\section{METHODOLOGY}

This section discusses how the data was collected, the measures that were used to examine variables in this study and how the data was analysed.

Doing research on conflict associated with process improvement projects can be difficult. Managers are often not keen to disclose information regarding internal conflict and negative issues that arise from cross-functional process improvement projects. To overcome this difficulty, the first author personally contacted senior managers at seven South African automotive manufacturing firms. Each manager was sent a copy of the questionnaire and asked to forward the questionnaire to persons within their departments who had recently been involved in a cross-functional process improvement project.

\section{Measures}

Variables in the model were measured using a questionnaire. Wherever possible in this study, previously developed measures were used. The questionnaire items are shown in the Measurement Appendix. The discussion of how the measure for each variable was developed follows.

\section{Conflict}

Following Jaworski and Kohli (1993), we measured conflict using likert scale items. Conflict was measured by averaging responses to seven items which gauge the extent to which there is conflict between departments. Questions attempted to ascertain to what extent people from different departments get along with each other.

\section{Performance Measurement Systems}

This study draws on the work of Chenhall (2005) who developed a measure of the use of performance measurement systems to achieve strategic alignment. The questionnaire items used sought to ascertain the extent to which performance measurement systems promote interdepartmental collaboration.

\section{Reward Systems}

A number of researchers have examined reward systems in different contexts, a measure that would be appropriate for this study could however not be found, and hence a new measure based on the literature and initial interviews with managers was developed. The measure aimed to ascertain the extent to which rewards motivated individual performance as well as collective performance.

\section{Formalization}

Drawing on the work of Ruekert and Walker, 1987; and Jaworski and Kohli 1993, a four-item scale was developed. The scale measures the extent to which roles and responsibilities are clearly defined, specifically in the context of cross-functional process improvement projects.

\section{Data Analysis}

A two staged approach was used to analyse the data. The first stage involved doing exploratory factor analysis in order to examine the underlying structure of the data. The reliability of the item to factor structure that emerged from the exploratory factor analysis was evaluated by computing Cronbach's Alpha for each factor.

The second stage of the research involved measuring the association between the variables. Pearson correlation analysis was used to measure whether any association was present and the statistical significance of this association. 
The correlation coefficient ' $r$ ' indicates the strength of the association between the two variables and is shown in Table 2. The larger the value of ' $r$ ', the stronger the linear association between the variables. The level of significance of each association is also shown in Table 2. Statistica version 7 was used for all data analysis.

\section{FINDINGS}

The respondents comprised eighteen manufacturing managers, six project managers, five research and development managers, and, three information technology managers. A total of 32 responses were received. Table 1 shows the descriptive statistics for each measure.

Table 1: Descriptive statistics and reliability measures for variables

\begin{tabular}{lccll}
\hline Construct & $\begin{array}{c}\text { Number } \\
\text { Items }\end{array}$ & $\begin{array}{c}\text { of } \\
\text { alpha }\end{array}$ & $\begin{array}{l}\text { Cronbach } \\
\text { alph }\end{array}$ & $\begin{array}{l}\text { Standard } \\
\text { Deviation }\end{array}$ \\
\hline $\begin{array}{l}\text { Cross-functional conflict } \\
\text { Performance measurement }\end{array}$ & 7 & 0.84 & 2.92 & 0.77 \\
$\begin{array}{l}\text { systems } \\
\text { Reward systems }\end{array}$ & 7 & 0.83 & 3.47 & 0.73 \\
Formalisation & $5^{*}$ & 0.70 & 3.33 & 0.78 \\
& 4 & 0.85 & 3.11 & 0.90 \\
\hline
\end{tabular}

* Originally 7 items (2 were removed after factor analysis)

Table 1, also shows the number of items used for each measure and the computed Cronbach alpha. The Cronbach alpha is 0.7 and above for all variables, and this is an indication that the measures used are reliable. In examining the expected factor pattern compared to actual factor loadings it was noted that two items from the reward systems factor did not load as expected, and that removing these two items from the reward systems variable would improve the reliability of the factor greatly. This was therefore done.

Table 2: Pearson correlation between focal variables

\begin{tabular}{lllll}
\hline & $\begin{array}{l}\text { Cross-functional } \\
\text { Conflict }\end{array}$ & $\begin{array}{l}\text { Performance } \\
\text { measurement } \\
\text { systems }\end{array}$ & $\begin{array}{l}\text { Reward } \\
\text { systems }\end{array}$ & Formalisation \\
\hline $\begin{array}{l}\text { Cross-functional } \\
\text { conflict }\end{array}$ & 1.00 & & \\
$\begin{array}{l}\text { Performance } \\
\text { measurement systems }\end{array}$ & -0.31 & 1.00 & & \\
& & & & \\
Reward structure & $-0.40^{*}$ & $0.52^{* *}$ & 1.00 & \\
Formalisation & $-0.48^{* *}$ & $0.77^{* * *}$ & $0.59^{* * *}$ & \\
& & & & \\
\hline
\end{tabular}


$\mathrm{p}<0.05^{*}, \mathrm{p}<0.005^{* *}, \mathrm{p}<0.001^{* * *}$ (two-tailed test)

The association of three organisational control mechanisms with conflict within cross-functional projects was examined (Table 2). Of the three organisational control mechanisms investigated, formalisation can be seen to have the strongest and most significant negative correlation with crossfunctional conflict $(r=-0.48, p<0.005)$.

The correlation analysis (Table 2) showed that reward structure and formalization had a significant negative association with conflict, indicating support for hypothesis 2 and hypothesis 3 . While performance measurement systems was expected to have a significant association with conflict (Chenhall, 2005), the correlation between performance measurement systems and conflict was not significant (at the 95\% confidence level), indicating that hypothesis 1 was not supported.

The findings indicate that in process improvement projects, the role of a clearly articulated project structure has a stronger influence than reward incentives and performance measures on crossfunctional conflict. Griffin et al. (2007), note that although attention is being paid to performance measurement and reward systems by managers, business environments are very complex and designing appropriate performance measurement and reward systems to promote cross-functional teamwork is difficult.

The findings of this study suggest that explicit processes and clearly defined roles lower conflict. This finding is supported by the work of Griffin and Hauser (1996) who argue that clear processes need to be established for any cross-functional team activity.

When employees are assigned to process improvement projects requiring cross-functional team work, they are taken out of their usual functional context (where their roles may be relatively well-defined) and put into a new context. The new context spans different functional areas. This often gives rise to ambiguity and confusion over specific roles and responsibilities of the individuals comprising the team. Definition and clarity in this uncertain context helps to alleviate the conflict associated with this uncertainty.

While some researchers have suggested that formalization will negatively influence cross-functional teamwork as it constrains freedom, this perspective has been questioned in the recent literature (Sine, Mitsuhashi and Kirsch, 2006). The findings from this study support these recent arguments, as formalization seems to reduce conflict levels within cross-functional organizational teams, and improve teamwork.

An additional finding from this study is that formalization in project structure, performance measurement and reward systems are all complementary. The strong, positive, significant correlations between formalization and performance measurement systems $(r=0.77, p<0.001)$ and between formalization and reward systems $(r=0.59, p<0.005)$ indicate that these organizational control mechanisms support each other in reducing conflict within cross-functional projects. This is useful as it suggests that while formalization in project structure may have the strongest influence on conflict; managers should not ignore performance measurement and reward systems.

\section{IMPLICATIONS FOR MANAGEMENT PRACTICE}

These findings yield interesting implications for management practice. The first implication is that managers need to be aware that putting individuals from different functions into groups in order to undertake a process improvement or implement a change creates conflict. Secondly, this conflict can be mitigated by designing and utilizing certain organizational control mechanisms. Thirdly, developing a clearly defined project structure can help to reduce the conflict associated with role ambiguity and uncertainty. Finally, it is also worthwhile for managers to think creatively about designing reward systems that are inclusive and that reward both individual as well as team work. 


\section{CONCLUSIONS}

This paper reports on an exploratory study conducted in the automotive industry in South Africa. The researchers investigated the role of organizational control mechanisms in reducing conflict within cross-functional projects. The research aimed to increase our understanding regarding whether and how formalization, performance measurement and reward systems reduce conflict within teams.

A negative effect of high levels of conflict within project teams is the loss of time. The loss of time is particularly problematic in industries where meeting deadlines is important, and in industries which involve the design and manufacture of complex products such as the automotive industry. This study has reinforced the need to better understand conflict and has contributed to our understanding of how the examined organizational control factors influence conflict. More generally, these findings imply that cross-functional conflict among teams can impede organizational responsiveness and corporate performance if appropriate control mechanisms for individual and team-oriented work are not implemented.

\section{FUTURE RESEARCH}

Further research is required to validate the findings from this study and to enable a better understanding of how organizational control mechanisms work within firms to reduce conflict. In order to understand the degree to which the findings of this study are generalizable to other contexts, further study will be needed on a larger scale and in different industry sectors in different countries. In this paper we have not explored other factors that may contribute to reducing conflict, such as leadership style or organizational climate. This study represents a starting point and it would be useful to include these types of factors in future research.

\section{REFERENCES}

Barnes J, Kaplinsky R \& Morris M. 2003. Industrial Policy in Developing Economies: Developing Dynamic Comparative Advantage in the South African Automobile Sector. Unpublished paper. [Online] Available from: http:/www.ids.ac.uk/ids/global/pdfs/RJandJB03.pdf [Accessed: 11/07/ 2007].

Bodewes WEJ. 2002. Formalization and Innovation Revisited. European Journal of Innovation Management, 5(4):214-223.

Cadsby CB, Song F \& Tapon F. 2007. Sorting and Incentive Effects of Pay for Performance: An Experimental Investigation. Academy of Management Journal, 50(2):387-405.

Chenhall RH. 2005. Integrative Strategic Performance Measurement Systems, Strategic Alignment of Manufacturing, Learning and Strategic Outcomes: An Exploratory Study. Accounting, Organizations and Society, 30:395-422.

Dawes PL \& Massey GR. 2005. Antecedents of Conflict in Marketing's Cross-Functional Relationship with Sales. European Journal of Marketing, 39(11/12):1327-1344.

Fishman C. 2000. Creative Tension. Fast Company, 35:359-372.

Gerwin D. 2004. Coordinating New product Development in Strategic Alliances. Academy of Management Review, 29(2):241-257.

Griffin MA, Neal A \& Parker SK. 2007. A New Model of Work Role Performance: Positive Behaviour in Uncertain and Interdependant Contexts. Academy of Management Journal, 50(2):327-347.

Griffin A \& Hauser JR. 1996. Integrating R\&D and Marketing: A Review and Analysis of the Literature. Journal of Product Innovation Management, 13:191-215. 
Jassawalla AR \& Sashittal HC. 2000. Inter-Functional Dynamics in New Product Development. Research Technology Management, 43(1):46-9.

Jaworski BJ \& Kohli AK. 1993. Market Orientation: Antecedents and Consequences. Journal of Marketing, 57(3):53 -70.

Kaplan D. 2004. Manufacturing in South Africa over the Last Decade: A Review of Industrial Performance and Policy. Development Southern Africa, 24(4):623-644.

Mantel SJ, Meredith JR, Shafer SM \& Sutton MM. 2005. Project Management in Practice. USA: Wiley.

National Association of Automobile Manufacturers of South Africa. 2008. [Online] Available from: http://www.naamsa.co.za [Accessed: 30/08/2008].

OPP Report. 2008. Fight, Flight or Face it? [Online] Available from: http://www.opp.eu.com [Accessed 16/10/2008].

Parker H. 2007. An Analysis of Buyer-Supplier Collaboration in the South African Textile Industry. Acta Commerci, 7:207-217.

Perks H \& Riihela N. 2004. An Exploration of Inter-Functional Integration in the New Service Development Process. The Service Industries Journal, 24(6):37-63.

Phillips L. 2008. Poor Conflict Management Cost UK plc Billions. People Managenment. 16 October 2008. [Online] Available from: http://www.peoplemanagement.co.uk/news [Accessed 16/10/2008].

Podsakoff PM, MacKenzie SB \& Bommer WH. 1996. Transformational Leader Behaviours and Substitutes for Leadership as Determinants of Employee Satisfaction, Commitment, Trust, and Organizational Citizenship Behaviours. Journal of Management, 22(2):259-298.

Ruekert RW \& Walker OC. 1987. Marketing's Interactions with Other Functional Units: A Conceptual Framework and Empirical Evidence. Journal of Marketing, 51:1-19.

Sine WD, Mitsuhashi H \& AD Kirsh. 2006. Revisiting Burns and Stalker: Formal Structure and New Venture Performance in Emerging Economic Sectors. Academy of Management Journal, 49(1):121132.

\section{MEASUREMENT APPENDIX}

Cross-functional Conflict (Cronbach alpha $=\mathbf{0 . 8 4}$ )

- Most departments get along well with each other

- When members of several departments get together, tensions frequently run high

- People in one department generally dislike interacting with those from other departments

- Employees from different departments feel that the goal of their respective departments are in harmony with each other

- Protecting one's departmental turf is considered to be a way of life

- There is little or no interdepartmental conflict

\section{Performance Measurement Systems (Cronbach alpha $=0.83$ )}

- Links between the policy of my department and business strategy are clearly formulated and pursued

- Senior managers have a general understanding of how products, markets and processes of my department interact and manage these interactions across functions

- Investments in my department are screened for consistency with business strategy 
- The performance measurement system provides consistent and mutually reinforcing links between current operating performance of my work group and long term strategies of my business unit

- The performance measurement system links together all business unit activities to the achievement of goals and objectives of the organization

- The performance measurement system shows how activities of my business unit affect activities of other units within the organization

- The performance measurement system is produced in a fully documented form, which provides a record for evaluating performance

Formalisation (Cronbach alpha $\mathbf{= 0 . 8 5 )}$

- Roles are clearly defined

- Everybody knows the processes and follows them

- There is no role ambiguity

- All processes are well documented

Reward Systems (Cronbach alpha $=0.70$ )

- I am rewarded for individual achievements

- A proportion of my salary consists of bonuses for individual performance

- Teams are recognized for collective achievements

- A component of each team member's compensation is tied to collective performance

- Team performance is remunerated in the form of financial or non financial rewards 